\title{
EL SACERDOCIO DE LOS FIELES Y EL MINISTERIAL EN EL PRIMER CAPÍTULO DE LA PRESBYTERORUM ORDINIS EN EL CINCUENTENARIO DEL CONCILIO VATICANO II
}

\author{
César Buendía Romero \\ Universidad Católica Sedes Sapientiae \\ cbuendia@ucss.edu.pe
}

Resumen: En este trabajo se pretende manifestar la labor del Concilio Vaticano II por ayudar al hombre en el divorcio que existe entre los hombres a causa de la envidia. Es difícil evitarla. Entre el laico y el ministro de los sacramentos siempre ha habido, y no procede del Señor, cierta envidia, el pecado diabólico, pues por envidia entró la muerte en el mundo (Sab 1, 13-15), y no es bueno que eso exista en la Iglesia. En realidad, Dios, que en Cristo ha buscado hasta la muerte a la oveja perdida, con riesgo y sacrificio de sí mismo, no nos ha mostrado que la más pequeña de las ovejas, o la más pecadora, sea menos amada. Por eso, el Concilio Vaticano II, en la Presbyterorum ordinis, entre otros documentos, ha aclarado contundentemente esta realidad de la Iglesia. Un análisis de los aspectos más relevantes de este documento permitirá identificar que no se ha caído en la alternativa protestante, tan tocada de lucha de clases, de oposición entre el ministerio y el laicado, sino que a ambos los ha englobado en la misma misión sacerdotal, la intercesión y la entrega, y a uno le ha encargado especialmente al otro, al ministerio el servicio del laicado, y el amor del Pastor, que es Cristo. 
Palabras Clave: Presbyterorum ordinis, Concilio Vaticano II, sacerdocio ministerial, laicado, secularización, evangelización, misión, Eucaristía, acción pastoral.

\section{THE PRIESTHOOD OF THE FAITHFUL AND THE MINISTERIAL IN THE FIRST CHAPTER OF THE PRESBYTERORUM ORDINIS ON THE FIFTIETH ANNIVERSARY OF II VATICAN COUNCIL}

Abstract: This paper aims to show the work of Vatican II to help man in divorce between men because of envy. It is difficult to avoid. Among the secular and the Minister of the Sacraments has always been, and not from the Lord, some envy, evil sin, because of envy death entered the world (Sat 1, 13-15), and that's not good exists in the Church. In reality, God, who in Christ has sought to death the lost sheep, with risk and sacrifice of himself, we have shown that the smallest of the sheep, or the most sinful, less beloved. Therefore, the Second Vatican Council, in the PO and other documents, has clarified conclusively the reality of the Church. An analysis of the most relevant aspects of this document will identify that has not fallen into Protestant alternative, as played by class struggle, the opposition between the ministry and the laity, but has encompassed both the priestly mission in the same, intercession and delivery, and one was specially commissioned to other service ministry of the laity, and the love of the Pastor, who is Christ Keywords: Second Vatican Council, the ministerial priesthood, laity, secularization, evangelism, mission, Eucharist, pastoral. 


\section{INTRODUCCIÓN}

1 Concilio Vaticano II siguió un período confuso en torno al
sacerdocio. Se dio una secularización masiva y un abandono de
la Iglesia por parte de muchos. Es necesario, pues, repasar a esta distancia los documentos del Vaticano II que intentaron dar luz. Y, en este momento, repasamos la Presbyterorum ordinis (PO) sobre el presbiterado católico.

El Vaticano II no significó, como se suele pensar, un acercamiento al mundo en el sentido de una aceptación de la secularización. Significó una pérdida de complejos, una profesión de fe en la evangelización como obra de Dios, y un acercamiento al mundo para ayudarle a transformarse. Evidentemente también una poda. Había cosas por abandonar y otras por descubrir.

No se trataba exacta y principalmente de un reconocimiento de culpas, porque sí que lo hubo; sino más bien una conversión de la Iglesia a su centro. Asimismo, se trata de un acercamiento a Dios y a su plan para poder evangelizar de nuevo el mundo, el actual. Es decir, el fin es acercarse al mundo con la sonrisa del Padre del Hijo Pródigo.

La Iglesia es una. Por eso, independientemente de la función de cada uno, la Iglesia debe vivir la unidad. Y esa unidad es tan profunda como la unidad del cuerpo humano. ${ }^{1}$ Es vital, y el Concilio en la Lumen gentium

1 Lumen gentium 7: «Y del mismo modo que todos los miembros del cuerpo humano, aun siendo muchos, forman, no obstante, un solo cuerpo, así también los fieles en Cristo (Cf. 1 Co 12, 12). También en la constitución del cuerpo de Cristo está vigente la diversidad de miembros y oficios. Uno solo es el Espíritu, que distribuye sus variados dones para el bien de la Iglesia según su riqueza y la diversidad de ministerios (1 Co 12,1-11). Entre estos dones resalta la gracia de los Apóstoles, a cuya autoridad el mismo Espíritu subordina incluso los carismáticos (Cf. 1 Co 14). El mismo produce y urge la caridad entre los fieles, unificando el cuerpo por sí y con su virtud y con la conexión interna de 


\section{CÉSAR BUENDÍA ROMERO}

(LG), al poner al Pueblo de Dios antes que la constitución jerárquica (capítulo II y III respectivamente), quiso enseñar que la igualdad es más profunda que las diferencias.

Mas eso no significó, como algunos dicen, una especie de valoración del laico en detrimento del sacerdote; es decir, un dar la razón en este punto a los protestantes. Significó más bien - y una somera mirada a la $L G$ será suficiente para comprobarlo- una valoración del papel de la jerarquía eclesiástica (N. 18 en adelante) y, en especial, de los obispos, que no se había dado nunca, ni siquiera en Trento. La valoración del laico tampoco fue una corrección de Trento. Aquel fue un concilio tan condicionado por las circunstancias, que tuvo que poner un freno sin afirmar lo positivo. No

los miembros. Por consiguiente, si un miembro sufre en algo, con él sufren todos los demás; o si un miembro es honrado, gozan conjuntamente los demás miembros (Cf.1 Co 12,26).

La Cabeza de este cuerpo es Cristo. Él es la imagen de Dios invisible, y en El fueron creadas todas las cosas. Él es antes que todos, y todo subsiste en El. Él es la cabeza del cuerpo, que es la Iglesia. Él es el principio, el primogénito de los muertos, de modo que tiene la primacía en todas las cosas (cf. Col 1,15-18). Con la grandeza de su poder domina los cielos y la tierra y con su eminente perfección y acción llena con las riquezas de su gloria todo el cuerpo (Cf. Ef 1,18-23).

Es necesario que todos los miembros se hagan conformes a Él hasta el extremo de que Cristo quede formado en ellos (Cf. Ga 4,19). Por eso somos incorporados a los misterios de su vida, configurados con Él, muertos y resucitados con Él, hasta que con Él reinemos (Cf. Flp 3,21; 2 Tm 2,11; Ef 2,6; Col 2,12, etc.). Peregrinando todavía sobre la tierra, siguiendo de cerca sus pasos en la tribulación y en la persecución, nos asociamos a sus dolores como el cuerpo a la cabeza, padeciendo con Él a fin de ser glorificados con Él (cf. Rm 8,17).

Por Él "todo el cuerpo, alimentado y trabado por las coyunturas: y ligamentos, crece en aumento divino" (Col 2, 19). Él mismo conforta constantemente su cuerpo, que es la Iglesia, con los dones de los ministerios, por los cuales, con la virtud derivada de Él, nos prestamos mutuamente los servicios para la salvación, de modo que, viviendo la verdad en caridad, crezcamos por todos los medios en Él, que es nuestra Cabeza (Cf. Ef 4,11-16 gr.)». 
obstante, todos sabían en Trento que los laicos eran no solo necesarios, sino el objeto de la preocupación de la Iglesia y, por tanto, sus auténticos protagonistas. Así, se vio en la reacción católica de verdadera conversión, especialmente con todo lo que rodeó a los Ejercicios de san Ignacio. De ahí que la afirmación de los pastores no es una degradación de los fieles, como la afirmación de los fieles no es una victoria sobre sus pastores. Marx está lejos de la realidad del Reino.

Entonces, ¿por qué el periodo que siguió al Vaticano II ha sido tan convulso, tan terriblemente traumático? No es, a mi entender, por el propio Vaticano II. La política de defensa fanática había llegado a su término, y el Vaticano II pasó a la iniciativa, a comprenderse sin perder la identidad, a reconstruir la unidad perdida. En el camino muchos confundieron el diálogo con la renuncia a la propia identidad, a la verdad de la que la Iglesia es depositaria, o se sintieron tan del mundo que se olvidaron de que eran de Dios.

El Concilio intentó aclarar muchas aporías que estaban en el ambiente y en la reflexión teológica de ese entonces. Si lo hubieran leído inteligentemente no hubiera sido tan traumático el período posterior y el actual. Por eso es necesario releer el Concilio.

Por otra parte, démonos cuenta en primer lugar que este período no ha sido más traumático que el que se vivió después de Trento, en la Guerra de los Treinta Años en que Europa quedó desangrada y devastada, con gran número de pérdidas humanas y materiales y dividida por más de tres centurias (se perdió la mitad de la población y se arruinó toda la economía, además de no poder evitar la división moral de Europa), ni más traumática que las persecuciones romanas, ni más que el período posterior a la revolución francesa, ni más traumática que las guerras mundiales. No. 
Más bien mucho menos. En consecuencia - y, a pesar de todo—, sí hemos de ver en todas las épocas la Providencia, especialmente en esta. Dios, en medio de la locura de los hombres, actuaba. Démonos cuenta también de que si no hubiera proclamado el Vaticano II la necesidad de Cristo que tiene la sociedad y cada una de sus actividades, y la correspondencia entre lo razonable y lo que propone la Iglesia (aun siendo necesario para aceptar la Revelación la asistencia del Espíritu y una rápida ojeada a la Gaudium et Spes lo confirma), la degradación de la sociedad y de la Iglesia hubiera sido, si cabe, mucho peor.

\subsection{La Presbyterorum ordinis, el decreto sobre los sacerdotes}

El Concilio Vaticano II tuvo presentes cuatro antecedentes fundamentales $\mathrm{y}$, ciertamente, un talante eclesial de apertura anticipado por el buen Juan XXIII: (a) el concilio de Trento, (b) el Concilio Vaticano I, (c) el racionalismo modernista y $(\mathrm{d})$ el ateísmo contemporáneo, especialmente el marxista. Sin embargo, se había dado ya en la Iglesia un cambio: el movimiento bíblico, el patrístico, el litúrgico, el teológico, y aquel de los grandes escritores, como León Bloy, Bergson, Maritain, Péguy, Marcel, Bernanos, Mauriac, Claudel, Mounier, Guitton, y el italiano Romano Guardini, y, más lejano en el espacio pero cercano en los interrogantes, Dostoyevsky. Cada documento conciliar, pues, tiene detrás a los obispos que lo escribieron, a los teólogos que lo asesoraron y a los escritores que lo inspiraron, pero, sobre todo, a los problemas que lo motivaron. 


\subsection{Repaso de los cuatro antecedentes}

Trento $^{2}$ salva del naufragio a la Iglesia acercándola a su ideal: una Iglesia que vive la fe. Fue una verdadera reforma de la Iglesia, pero en su reflexión teológica simplemente intentó, como era lógico, poner una barrera a los más clamorosos errores. Afirmó lo siguiente: (a) la primacía y la necesidad de la gracia contra los humanistas, y la necesidad y la existencia de la libertad frente a los deterministas protestantes; (b) la necesidad de los sacramentos y la voluntad de Cristo de fundar la Iglesia, así como de su visibilidad frente al individualismo, especialmente el protestante, y al iluminismo intimista, $y$ (c) la necesidad en especial y existencia del sacramento del orden, sobre todo en orden a dos sacramentos esenciales: la Penitencia y la Eucaristía.

El Vaticano I, ${ }^{3}$ en la línea de Trento, afirma que la asistencia del Espíritu Santo a la Iglesia se concreta en la infalibilidad en ciertas cuestiones y momentos, y la infalibilidad pontificia en materia de fe y de moral cuando enseña ex cathedra; es decir, con toda su autoridad. Y, en otro tema, el Vaticano I afirma la razonabilidad de la fe, pero niega el racionalismo que hacía inútil la revelación.

El modernismo siguió en la línea del racionalismo, negando la posibilidad de la Revelación y, por tanto, incluso la divinidad de Cristo. A ello responde primero el Papa Pío X y después el Vaticano II. Ambos afirman la posibilidad y la realidad de la Revelación, y resaltan, además, la asistencia del Espíritu a la Iglesia en todos sus miembros, especialmente en el Colegio Episcopal. ${ }^{4}$

2 Ver Misioneros del Sagrado Corazón del Perú. <http://www.mscperu.org/ biblioteca/1magisterio/denzinger/denzinger_2b.htm>, en la parte del Concilio de Trento.

3 Ibidem.

4 Véase encíclica Pascendi; disponible en La Santa Sede: <www.vatican.va/holy_father/ 
Mas el racionalismo ha evolucionado. Ya no niega como en el modernismo la Revelación, niega a Dios. Es ateísmo. Por eso, el Concilio (Cf. GS 19-21) afirmará no solo la posibilidad del hombre de conocer naturalmente a Dios como había dicho el Concilio Vaticano I, sino que analizará las razones que aporta el ateísmo, y llegará a decir que el hombre únicamente encuentra su verdadera vocación en Cristo, de donde se hace necesario predicarle y conocerle.

Sin embargo, el Concilio Vaticano II dice mucho más. La Constitución sobre la Iglesia, la Lumen gentium, va a afirmar tres principios: (a) la ordenación de todos los hombres a la salvación, (b) la voluntad salvífica universal de Dios y (c) la mediación Cristo cuyo cuerpo es la Iglesia. De estos, los hombres están ordenados a la Iglesia y muchos de ellos unidos de algún modo a ella por algún vínculo, que constituye el medio de su propia salvación. Esto significa, por otro lado, la infalibilidad de la Iglesia, puesto que es obra de Dios, y no debe confundir a los hombres de las distintas épocas. Es lo que después dirá la Dominus Iesus en otro contexto, para evitar el relativismo doctrinal y, especialmente, cristológico y eclesiológico.

Era necesario explicar el papel de la Biblia en la Iglesia tras afirmaciones tan importantes. Y se puso en evidencia en la Constitución sobre la Revelación, la Dei verbum (DV), que la Iglesia, aun estimando y animando el papel de los investigadores, es la verdadera intérprete de la Palabra. En este sentido, la conserva de algún modo en sí misma, como conserva la Presencia de Cristo (Cf. DV 8; 10).

Las constituciones sobre Liturgia (Sacrosanctum Concilium) y sobre la Iglesia en el mundo actual (Gaudium et Spes) no se pueden entender sin las pius_x/encyclicals/documents/hf_p-x_enc_19070908_pascendi-dominici-gregis_ sp.html>. Asimismo, léase el decreto Lamentabili sine exitu; disponible en Stat Veritas: http://www.statveritas.com.ar/Magisterio\%20de\%20la\%20Iglesia/DECRETO_ LAMENTABILI_SINE_EXITU.pdf>. 
anteriores. La primera acentúa la presencia de Cristo en los sacramentos y, especialmente, en el de la Eucaristía, y, sin embargo, anima a la purificación de la liturgia y la aproximación al Pueblo de Dios a través de su traducción a la lengua popular. La segunda estudia los temas del momento (familia, economía, política, ateísmo) desde la antropología, es decir, desde el hombre que nos ha sido revelado en Cristo.

No se puede leer la $P O$, sobre la vida y el ministerio de los presbíteros, sin tener en cuenta toda esa enorme reflexión. En el caso concreto de los presbíteros la afirmación de Trento de que Dios fue el que los quiso y su sacramento está instituido por Cristo es la piedra miliar; mínima, pero necesaria. La reflexión posterior de la $P O$ será más bien hacer comprender la naturaleza y misión del sacerdote en medio del mundo y su especial espiritualidad, sobre todo en el mundo actual, tan transformado.

¿Qué problemas vislumbra el Concilio que tiene o va a tener el presbítero?

No estamos en Trento. La galopante secularización actual ya se veía venir en el momento en que el papa Juan XXIII convocó el Concilio. Ese momento preparaba un mundo nuevo. Si en 1789 cayó el Antiguo Régimen, ahora se ponía en duda exactamente cosas que jamás se habían tocado. Pensemos en Wittgenstein, en Nietzsche, en Freud, en Feuerbach. No en vano se había dado el ateísmo, el racionalismo que ya fue el caballo de batalla del Vaticano I. Y los clérigos eran personas que leían, atentas a los medios de comunicación, posibles contagiados de estas doctrinas. Su tarea se vuelve difícil en medio de la secularización ambiental. Pierde su estatus, es decir, pierde su influencia social, y le ataca el racionalismo que invadió especialmente la interpretación bíblica alentado por Darwin y las teorías científicas. 
Independientemente de ello se ha producido la invasión de cine y televisión. Dicho escenario ha significado no solo la globalización, sino también la diversificación del pensamiento y de los maestros. Cine, televisión, internet y otros medios son maestros nuevos, distintos y distantes de los tradicionales.

Por otro lado, se sufre la persecución propia del mundo moderno, en el que, sin la fe, nadie puede sostenerse. El presbítero ha perdido relevancia social. Es probado con la soledad, con la tentación del éxito, con la dificultad para la oración en un mundo que solo cree en lo material, o en su razón, pues son alabados aquellos que niegan exactamente lo que la Iglesia cree, y su presencia entre los hombres parece inútil, pues no es escuchado aparentemente. ${ }^{5} \mathrm{Y}$ digo aparentemente porque ocurre lo contrario. La noticia que esperan es la caída del que representa a la Iglesia.

Es necesario que el sacerdote comprenda su propio valor, su propio papel, su propia utilidad. Un decreto que intentaba hablar de la economía sacerdotal se volvió de golpe muy importante. Y habló de la naturaleza del presbiterado.

Por otro lado, el protestantismo está ahí. Hasta ahora en el patio de atrás. Pero, actualmente, parece a muchos un discurso acertado. ¿Dónde instituyó Cristo a los presbíteros? ¿Qué es un sacramento, algo de la Iglesia o algo de Cristo? Cuesta afirmar la institución divina de los mismos.

El texto de la $P O$ se plantea el problema de la institución divina del sacerdocio católico, de su relación con los obispos, de la relación con la Iglesia, y, sin solucionar ciertos temas, sobre todo, de cómo vivirlos. ¿Qué temas? Los que ya hemos insinuado. No quiere, sin embargo, el Concilio 5 Pablo también fue rechazado, pero decía que somos un espectáculo y están fijándose en nosotros (1Cor 4,9). Él sabía que no resultaba indiferente su actuación ante el mundo. La reflexión de Sb 2,17 iba por ese camino en el Antiguo Testamento cuando prueba al justo el malvado con el sufrimiento. 
dar soluciones provisionales o tomar partido entre escuelas. Y, por eso, en cierto sentido, deja a los teólogos posteriores aclarar ciertos puntos. El Concilio intenta que, vueltos los ojos al Señor, el presbítero viva de la fe.

Conoce el Concilio la influencia imparable de los medios de comunicación y el ocaso de un mundo rural donde el sacerdote ocupa el papel que la sociedad necesita y le confía. Asimismo, entiende la irrupción de un mundo nuevo donde el sacerdote habrá de presidir una comunidad que quizá sea minoritaria y viva en una persecución implícita en medio de una sociedad que ya ha dado la espalda a la fe. Pero percibe la necesidad de que el sacerdote no sea simplemente una víctima o alguien que se parapeta y se esconde, sino que salga a dar la vida evangelizando. ${ }^{6}$

\section{PRIMERA AFIRMACIÓN IMPORTANTE: EL SACERDOCIO MINISTERIAL ES LA PARTICIPACIÓN DEL DE CRISTO}

He dicho que la primera preocupación del Concilio es señalar la institución divina del presbiterado. La afirmación en este sentido hay que entenderla en sentido dogmático, aunque se diga de modo aparentemente incidental. Muchas cosas importantes, para no hacer una declaración vinculante, se dicen así. Y un decreto tiene como finalidad aparente hablar de lo práctico. Pero nada es incidental. El decreto ha dejado claro que únicamente hay un ministerio, el de Cristo, y que, por tanto, de ese ministerio participa el presbítero católico:

6 «Y como se asignan a este Orden en la renovación de la Iglesia influjos de suma trascendencia y más difíciles cada día [...] Lo que aquí se dice se aplica a todos los presbíteros, en especial a los que se dedican a la cura de almas, haciendo las salvedades debidas con relación a los presbíteros religiosos» (PO 1). 


\section{CÉSAR BUENDÍA ROMERO}

Pues los presbíteros, por la ordenación sagrada y por la misión que reciben de los obispos, son promovidos para servir a Cristo Maestro, Sacerdote y Rey, de cuyo ministerio participan, por el que la Iglesia se constituye constantemente en este mundo Pueblo de Dios, Cuerpo de Cristo y Templo del Espíritu Santo. $(\mathrm{PO} 1)^{7}$

No se puede negar el carácter solemne de esta afirmación casi inicial en el documento, que ocupa el lugar principal en $P O 2$. Y hay que retener su carácter dogmático. Lo da por supuesto, puesto que ya lo dijo Trento. Pero afirma que la misión de Cristo se realiza en la Iglesia y que ese ministerio lo sirven los sacerdotes. No se dice que se realice exclusivamente esta misión a través de ellos, pero sí que se hace también y de modo particular, a través de ellos. ${ }^{8}$

El oficio es el de sacerdote, profeta y rey. Y a través de ese oficio se constituye la misma Iglesia como Pueblo de Dios, Cuerpo de Cristo y Templo del Espíritu. No se podía hablar más solemnemente que recordando la vinculación del ministerio y la misión de Cristo con la Iglesia y la Trinidad.

7 Lo vuelve a decir en PO2: «El ministerio de los presbíteros, por estar unido al Orden episcopal, participa de la autoridad con que Cristo mismo forma, santifica y rige su Cuerpo. Por lo cual, el sacerdocio de los presbíteros supone, ciertamente, los sacramentos de la iniciación cristiana, pero se confiere por un sacramento peculiar por el que los presbíteros, por la unción del Espíritu Santo, quedan marcados con un carácter especial que los configura con Cristo Sacerdote, de tal forma, que pueden obrar en nombre de Cristo Cabeza (Conc. Vat. II, Const. dogm. De Ecclesia, n. 10). Por participar en su grado del ministerio de los apóstoles, Dios concede a los presbíteros la gracia de ser entre las gentes ministros de Jesucristo, desempeñando el sagrado ministerio del Evangelio, para que sea grata la oblación de los pueblos, santificada por el Espíritu Santo (Rom, 15, 16)»

8 En PO 2 (vide cita anterior) señala además el carácter sacramental y la unidad del único sacramento del orden a pesar del grado, correspondiente a la unidad de la Iglesia. 
Aparte de dar una definición trinitaria preciosa de la Iglesia, ha indicado la necesidad de los presbíteros y la unidad del ministerio. El motivo es que es el mismo de Cristo, sin excluir el modo con el que los laicos también participan de la triple misión de Cristo. La unidad de esa misión, ejercida de modo diverso, se funda en la unidad final de la misma Iglesia y la unicidad de su Cabeza, Cristo. ${ }^{9}$

Creo que intenta, el Concilio, confutar algunas objeciones: (a) la del mundo moderno que niega lo sacramental, reduciendo la fe a una simple superstición minoritaria y (b) la de aquellos que conciben el sacerdocio más según su función que según su naturaleza. La función deriva de la naturaleza, y no al contrario, y la naturaleza es principalmente, al ser la de Cristo, ante el Padre. Sin embargo, por ser humana, está no solo en favor de los hombres, sino para ellos y ante ellos.

Lo sacramental está profundamente relacionado con lo visible, con lo profético, con la palabra, con lo inteligible, con lo humano. Hace visible lo invisible, hace comprensible lo que estaba oculto desde la creación del mundo. Realiza lo que significa, pero significa lo que realiza, porque tan importante es la realización como su comprensión. Dios siempre nos amó y de diversos modos nos lo mostraba, ahora plenamente por el Hijo (Heb $1,1)$.

Por eso, el Hijo, sacerdote, mediador, es el sacramento del Padre. El sacerdote lo es del Hijo. Ejerce, además, una función sobrenatural porque es instrumento de Cristo, Dios y hombre. El Concilio invita a los sacerdotes a vivir su misión desde Cristo. Aunque posiblemente haya entre

9 En LG 10 afirma de modo paladino esta unidad y esta necesidad mutua de sacerdotes y laicos: «El sacerdocio común de los fieles y el sacerdocio ministerial o jerárquico, aunque diferentes esencialmente y no sólo en grado, se ordenan, sin embargo, el uno al otro, pues ambos participan a su manera del único sacerdocio de Cristo» (Mediator Dei, 20 nov. 1947: AAS 39 [1947] 555). 
los presbíteros ambiciones humanas, el Concilio los invita a abandonarlas y vivir desde la fe. Ellos han de vivir en la fe esa misión, esperando en la vida eterna ver los resultados. Sin fe no se puede vivir esa misión, que después dirá «entre los hombres», pero no «como los hombres»; para ellos pero sin contagiarse de sus males y errores.

Da la impresión de algo más. La frase sugiere que Cristo se hace presente a través de los sacerdotes para los fieles. De modo que está invitando también a los fieles a estimar a sus sacerdotes, a verlos desde la fe, a ver en ellos al Señor en la Iglesia. La Lumen gentium había hablado de una presencia especial en el sacerdote (LG 7).

Mas habría que afirmar también otros puntos. En primer lugar, el presbítero que propone el decreto es, no solo el crucificado por los ajenos, sino el servidor de los propios, como lo fue Cristo. En eso, consiste su vocación y su honor. En segundo lugar, esa misma es la vocación de los mismos presbíteros, tantas veces ridiculizados e incomprendidos, $\mathrm{y}$ muchas veces escandalizados de la cruz que ello supone. Invisiblemente, el Crucificado está realizando por ellos el combate contra el mundo, que se siente también escandalizado de su presencia, como se sintió escandalizado de la presencia de Dios en él, en Cristo.

Veámoslo en concreto en el PO 2. Lo primero que explica es la complementariedad entre el sacerdocio común de los fieles, que tienen una misión específica, y el presbiteral. Comienza explicando el sacerdocio común: «En Él todos los fieles se constituyen en sacerdocio santo y real, ofrecen a Dios, por medio de Jesucristo, sacrificios espirituales, y anuncian el poder de quien los llamó de las tinieblas a su luz admirable (1 Pedr 2, 5 y 9)». ${ }^{10}$

10 PO 2: «El Señor Jesús, “a quien el Padre santificó y envió al mundo” (Jn 10, 36), hace partícipe a todo su Cuerpo místico de la unción del Espíritu con que Él está ungido (Mt 


\section{EL SACERDOCIO DE LOS FIELES Y EL MINISTERIAL EN EL PRIMER CAPÍTULO DE LA PRESBYTERORUM ORDINIS}

Lo propio del sacerdocio común, el de todos los fieles, es el sacrificio, pero espiritual. En realidad, la historia de la humanidad enseña que el hombre ha intentado encontrar a Dios. El sacrificio es el acto de amor que el hombre hace para reconocer a su Creador y Señor. Pero la historia enseña que el hombre, que no ve a Dios, ha pensado, ha dudado de si su sacrificio es acepto. Por tanto el fiel, si su sacrificio es aceptado, vive exactamente el sueño del hombre. Se llama al de laico espiritual en contraposición, en este caso al sacramental o visible. El fiel realiza espiritualmente su sacrificio aceptando la voluntad de Dios en su vida. Aparentemente es como los demás, espiritualmente está entregándose a Dios. Aparentemente, los laicos en su vida están trabajando con lo material, pero espiritualmente se lo ofrecen todo al Señor o al menos lo pueden hacer. Y eso es lo valioso. Y el sacerdote, en la Eucaristía, lo une sacramental, y por tanto, visiblemente; porque visible es la Iglesia y visible el pan y el vino, fruto de la tierra, de la vid y del trabajo del hombre, al sacrificio de Cristo. Lo simbólico de la ofrenda no quita la realidad de la vida. ${ }^{11}$

3, 16; Lc 4, 18; Act 4, 27; 10, 38): puesto que en Él todos los fieles se constituyen en sacerdocio santo y real, ofrecen a Dios, por medio de Jesucristo, sacrificios espirituales, y anuncian el poder de quien los llamó de las tinieblas a su luz admirable (1 Pedr 2, 5 y 9). No hay, pues, miembro alguno que no tenga su cometido en la misión de todo el Cuerpo, sino que cada uno debe glorificar a Jesús en su corazón (1 Pedr 3, 15) y dar testimonio de Él con espíritu de profecía (Lumen gentium, N. 35)».

11 PO 2: «Para que sea grata la oblación de los pueblos, santificada por el Espíritu Santo. "Por el ministerio de los presbíteros se consuma el sacrificio espiritual de los fieles en unión del sacrificio de Cristo, Mediador único, que se ofrece por sus manos, en nombre de toda la Iglesia, incruenta y sacramentalmente en la Eucaristía, hasta que venga el mismo Señor (1 Cor, 11, 26). A este sacrificio se ordena y en él culmina el ministerio de los presbíteros. Porque su servicio, que surge del mensaje evangélico, toma su naturaleza y eficacia del sacrificio de Cristo y pretende que "todo el pueblo redimido, es decir, la congregación y sociedad de los santos ofrezca a Dios un sacrificio universal por medio del Gran Sacerdote, que se ofreció a sí mismo por nosotros en la pasión, para que fuéramos el cuerpo de tan sublime cabeza" (De civitate Dei, 10, 6: PL 41, 284)». 
Así, el ministerio de los presbíteros une en la Eucaristía, que es el sacrificio de Cristo, su propia entrega y los sacrificios espirituales de los fieles. Pero su sacerdocio no solo es eso. Es también la apertura de los dones de Dios a los fieles, «en favor de los hombres»: «Y desempeñar públicamente, en nombre de Cristo, la función sacerdotal en favor de los hombres». ${ }^{12}$

En este pequeño texto, el que escribió esto parecía sufrir de complejo de culpabilidad. Parece que pide perdón por ser sacerdote. Tanta leña han hecho los protestantes contra los presuntos privilegios de los presbíteros que ahora estos tienen que pedir perdón por serlo. Y el Concilio defiende, puesto que no es la soberbia o la ambición el alma del presbítero; es la obediencia a Cristo que ha venido para servir. Lo especial de la vocación del presbítero se funda en la voluntad de Cristo.

Pero también el Concilio pretende señalar lo que debería primar. Esto es la unidad entre presbítero y laico. Dicha postura se sustenta en que aunque el modo de ejercerla sea diverso, la misión es una.

Es interesante que, al final del documento, proponga la supresión de los beneficios. Era un sistema económico propio de la época feudal que sobrevivía, pero que parecía tener un significado: el presbítero era alguien que poseía casi en propiedad un modus vivendi y pertenecía en consecuencia a una clase social. Aparecía, en segundo lugar, el servicio que ello imponía. Ahora, ocurre algo distinto: el Concilio pide al sacerdote el amor a las ovejas, y su sentido está en relación con Cristo y su Iglesia, su rebaño. Los componentes económicos se dejan en segundo plano.

12 PO 2: «Mas el mismo Señor, para que los fieles se fundieran en un solo cuerpo, en que "no todos los miembros tienen la misma función" (Rom, 12, 4), entre ellos constituyó a algunos ministros que, ostentando la potestad sagrada en la sociedad de los fieles, tuvieran el poder sagrado del Orden, para ofrecer el sacrificio y perdonar los pecados (Conc. Trident. Sess. 23, cap. 1 y can. 1: Denz., 957, 7, 961 [1764 y 1771]), y desempeñar públicamente, en nombre de Cristo, la función sacerdotal en favor de los hombres». 
Es claro que da una respuesta al marxismo que había acusado a la Iglesia de aliarse con el poder y tentaba a la misma de la división y de la lucha de clases. Ahora ha puesto el servicio a la sociedad como lema y objetivo. Esto es porque la Iglesia (Gaudium et Spes) sirve al mundo con la fe, y el sacerdote es la cara de la Iglesia.

Por otro lado, y finalmente, invita al presbítero a verse a sí, como había hecho con el hombre y con la familia, como un misterio de fe. Sin fe es imposible comprenderse ni llegar a la felicidad de cumplir con su propia vocación.

Si lo dice también es porque el ateísmo, o al menos la secularización, ha invadido las conciencias. Hay un peligro de vivir de forma meramente externa y activista la propia existencia presbiteral. Cuesta mucho sumergirse en la relación con Dios, tan relacionado esto con la reflexión profunda sobre la propia vocación y la formación permanente. El presbítero es alguien que está en diálogo con el que le envía en su nombre, Cristo. Y ya predique, ya acompañe, ya ore, ya celebre, ya aconseje o ya haga algún tipo de función caritativa material, es alguien cuyo sentido está en Cristo y, por tanto, alguien que tiene que vivir esa relación personal, independientemente del entorno, muchas veces hostil o indiferente, que le rodee.

Pone antes el sacerdocio de los fieles, el común, que el presbiteral. Ese orden es importante. El sentido evidente no es solo que los laicos no desaparezcan o no se molesten. Es porque el sacerdocio ministerial está al servicio del sacerdocio común. ${ }^{13}$

Pero qué es el sacerdocio, tanto el presbiteral como el común de los fieles. Por qué no insistir en lo profético que es comprensible y que los protestantes lo subrayaron indicando que todos pueden predicar. Por qué insistir en lo sacerdotal.

13 «Para el bien de los hombres» (PO 2). «En favor de los hombres» (PO 3). 
Lo sacerdotal es lo que se refiere a la intercesión, a la mediación, a estar ante el Señor por los demás (Heb 5,1). Coram Deo. Esta es una misión de la Iglesia, y, por tanto, de todo el pueblo de Dios, y es la oración. Pero es una misión sacramental y común, y por eso se ejerce de modo distinto por la comunidad y por el que la preside en el nombre del Señor.

Por otro lado, el Concilio quiere unir, a esta misión, la misión profética de Cristo y la pastoral, pero a nosotros nos resulta difícil comprender su misión específicamente sacerdotal, aunque sea inseparable de las anteriores. Poner lo sacerdotal en primer lugar no es aleatorio. Significa que Cristo está ante el Padre. La intercesión es su misión. El sacramento es un misterio ante el Padre. La muerte de Cristo es una oración ante el Padre. Y por ella el mundo es salvado y experimenta la resurrección y el perdón de los pecados, la puerta abierta. Después viene el buscar a las ovejas para que entren por esa puerta. El Concilio habla, en este caso, de entrega a Dios y a la misión a la que Dios le envía, y de sacrificio personal, el mismo que Cristo ofrece, inseparable de la confesión, de la martyria, de la cruz, del verdadero ejercicio de la profecía y de la realeza, o sea del pastoreo. No puede pastorear el que no da la cara en la batalla, el pastor es el que da la vida por las ovejas. La entrega al Padre es también lo que va a pedir a los laicos, y esa entrega es eucarística, unida a Cristo, y sacramental, oracional, previa a todo servicio a los hombres, pero unida al verdadero servicio, que es la confesión de la fe, la profecía. Por eso, la Iglesia se reúne y constituye cuando dos o más oran, es decir, cuando hay unidad en el sacramento eucarístico. Se hace visible el apoyo que unos reciben de otros en la confesión del mismo nombre y en la entrega amorosa de la fe.

¿Y la supuesta oposición entre el pastor y el fiel? El protagonismo es, a veces, llevado por el orgullo y la necesidad de aprobación social, la presa 
que se disputan los hombres, como si de una pelea de perros por un hueso se tratara. A veces es el dinero, otra el poder, otras la simple competencia y la victoria. Y muchas veces el protagonismo es suficiente para sentirse bien, como si el futuro fatal llegara irremisiblemente antes a los que no tienen quién les aplauda o como quien busca la gloria de los hombres y no la del Padre (Jn 5,44).

Jesús, en el Evangelio, habla de las riquezas que no aseguran la vida o los honores, que tampoco son nada. Recordemos a este respecto la parábola de Epulón y Lázaro o la del rico insensato. Jesús lo sabía y el Evangelio nos previene contra ello (Mt 20, 17-28) y suplicó insistentemente por la unidad, porque esa unidad es el signo de la unidad con el Señor. Una Iglesia donde hay partidos no es la de Cristo (1Cor 3). Los protestantes habían reclamado dos cosas en este punto, habían sospechado de la institución divina del sacerdocio y habían hablado de la opresión histórica del clero sobre el laicado. Trento había reaccionado declarando el sacramento y su carácter imborrable, y había reformado el clero, ${ }^{14}$ pero ello acepta implícitamente la falta de espiritualidad en el mismo. Debido a esto, decretó la constitución de seminarios donde se discerniera la vocación y se formara esta y al candidato a órdenes en todos los campos necesarios.

La Presbyterorum ordinis nos invita a poner la misión por encima del beneficio personal, porque ese es el sentido de la oblación sacerdotal,

14 Can. 9. Si alguno dijere que los clérigos constituidos en órdenes sagradas o los regulares que han hecho profesión solemne de castidad, pueden contraer matrimonio y que el contraído es válido, no obstante la ley eclesiástica o el voto, y que lo contrario no es otra cosa que condenar el matrimonio; y que pueden contraer matrimonio todos los que, aun cuando hubieren hecho voto de castidad, no sienten tener el don de ella, sea anatema. Dios, en efecto, no niega este don a quienes se lo piden rectamente y no consiente que seamos tentados más allá de aquello que podemos (Cf. 1 Cor 10, 13). DSH 1809-1810. En el aspecto económico obligó a la residencia e hizo lo posible por evitar las diferencias en el clero y la acumulación de beneficios obligando a la residencia episcopal. 
que debe ser vivida tanto por el laico como por el presbítero, aunque de distinta manera. Tal oblación en el caso del cristiano, que tanto lo es el presbítero como el laico, es la de la propia vida al servicio del Señor. Pero como representante de Cristo Cabeza y Pastor, el presbítero actúa en su nombre, y por tanto actúa el mismo Cristo, que une a su entrega la de la comunidad a la que sirve el presbítero.

Sin embargo, en ese caso, el del presbítero, a diferencia de los sacrificios espirituales que son el sentido de la actuación personal, aun influyendo la piedad personal del presbítero, no es esta lo decisivo, sino Cristo en cuyo nombre se actúa. Así aparece en la Presbyterorum ordinis 1. Es a través de él que Cristo realiza las acciones sacerdotales salvadoras, incluso la intercesión ante el Padre, especialmente en la Eucaristía, pues no es otro el sentido de la misma que es la actualización del sacrificio de la cruz. Pero el Concilio quiere que el presbítero se una a esto que realiza, que imite lo que conmemora.

Podríamos concluir de esta forma las meditaciones de la Presbyterorum ordinis sobre el sacerdocio común y el ministerial, de modo que no se pongan en contradicción sino más bien en complementación: ambos consisten en ofrecer un sacrificio, signo de amor al Dios que nos ha amado por su Hijo. Y, sorprendentemente, no son sacrificios nuevos. El sacrificio es el mismo que Dios ha ofrecido para lograr nuestro amor y manifestarnos el suyo: el sacrificio de sí mismo en su Hijo.

Así, la correspondencia entre el sacerdocio común y el ministerial es notoria: nos ofrecemos como fieles a Dios. Mas si bien todos, ante Dios, el presbítero ofrece uniéndolo al sacrificio de Cristo que se da en la Eucaristía.

La diferencia con los hermanos separados es patente: ellos piensan que nosotros presbíteros hemos robado a los laicos el protagonismo. No se 
trata de eso. Nosotros no podemos ofrecer otra cosa digna del amor de Dios más que a Jesús mismo, y con él a nosotros, como explica perfectamente la carta a los Hebreos. Pero no separados, sino como una sola Iglesia.

De modo que la mediación es compleja. En Cristo, como hombre, se ha unido la humanidad reconciliada y Dios, y a través de Él hemos conocido y creído en Dios. Esto es propio del sacerdocio común. Pero como tal ofrenda es eucarística, y como la comunidad se une a través de sus legítimos pastores, y como, también, el sacerdote ofrece a Cristo el sacrificio espiritual de los fieles y ofrece al Padre y a los fieles al mismo Cristo en la Eucaristía, el sacerdote ocupa un lugar especial, como instrumento de Dios y de los hombres.

Y no se diga que así el fiel queda separado de Dios por la burocracia sacerdotal, que el mediador se ha introducido en la relación alejando de sí a los dos extremos, que la cercanía de Dios ha sido de nuevo frustrada por la clase sacerdotal, que nada de ello aparece en la relación cercana de Jesús con los hombres y, especialmente, con los pecadores. Todo eso está en Lutero, ${ }^{15}$ que, en el fondo, dice que negamos la oración ardiente del publicano, la perseverante del ciego de Jericó al que los amigos de Jesús intentan alejarle de Él, de la hemorroísa que hace una oración ilegal y silenciosa, oraciones que llegarían directamente por Jesús a Dios Padre. No es cierto que estemos negando estas evidencias. Esa oración persiste. Pero no puede ser separada de la oración eucarística de Cristo, ni de la Iglesia. Y, dado que Cristo está en la Eucaristía, a la oración de Cristo presente en ella que se ofrece al Padre con el único sacrificio, el de la Cruz, que vale para siempre, se unen todas las demás oraciones y sacrificios.

15 A la nobleza cristiana de la nación alemana (1520). 


\section{LA MISIÓN DE PASTOR, LA CARIDAD}

Esa es la novedad del Nuevo Testamento. El sacerdote veterotestamentario estaba separado por la pureza ritual de un pueblo que oraba a través de él. Se consideraba que Dios no escucha a los pecadores (Jn 9,31). Ahora decimos que sí, pero después «preséntate a los sacerdotes» (Mt 8,1-4), «llama a los presbíteros de la Iglesia» (Sant 5,14), que la oración sacramental de la Iglesia no se opone a la particular y «a los que perdonen los pecados les serán perdonados» (Jn 20,23).

Mas el Concilio sabe que tenemos la tendencia, pecaminosa, de aprovecharnos de lo sagrado en provecho propio. Sabe que la Majestad divina, que debe ser amada y honrada - y, en el mismo sentido sus ministros, no en cuanto personas particulares, sino en cuanto ministros suyos-, puede convertirse en instrumento de separación, de clase social, de desprecio de los pobres. Esa es nuestra tentación, que aparece constantemente en el Antiguo Testamento y se repite mientras no estemos en el cielo (Cf. I Sam 2, 12- 36; 4, 1-22; Cf. Lev 3,3-5)

Sin embargo, no fue siempre así. Aquellos que eran honrados por los cristianos eran odiados por los paganos. Ciertamente eran sacerdotes para el sacrificio, porque eran los primeros que caían en la persecución. Sigue siendo así. Y el milagro es la alegría con que se puede vivir del cielo y no de la tierra. Esto es lo que pide el Concilio en este decreto.

El protestantismo se entiende en una situación diversa. Surge al final de la Edad Media. La separación entre clero y pueblo, tras la Edad Media en Europa, que privilegiaba al clero, era odiada por el pueblo, y el protestantismo tuvo mucho de reivindicación de la verdadera misión del presbítero. 


\section{EL SACERDOCIO DE LOS FIELES Y EL MINISTERIAL EN EL PRIMER CAPÍTULO DE LA PRESBYTERORUM ORDINIS}

El Concilio lo reconoce y lo intenta remediar. Así, la primera forma de remediar esta situación es decirle al sacerdote su misión exacta: la de pastor (PO 12):

Por el Sacramento del Orden los presbíteros se configuran con Cristo Sacerdote, como miembros con la Cabeza, para la estructuración y edificación de todo su Cuerpo, que es la Iglesia, como cooperadores del orden episcopal. Para la edificación del Cuerpo. La misión es el servicio a las ovejas de Cristo. El Buen Pastor da la vida por las ovejas. Las conoce y ellas le conocen. Busca y perdona a la oveja perdida. Cuida de la enferma. Las ama. Ésa es la misión del presbítero en unión con su Obispo, que significa vigilante. El decreto insiste en la caridad pastoral, en el amor del Pastor (Cf. LG 10). Quizá parezca entonces muy dispersa la vida del presbítero, pero no es así. Se define por la unión con Cristo, por su amor a Él, a quien sirve en sus ovejas. $Y$ ése es su sacrificio, el que ofrece al Padre, y, por lo mismo, el instrumento de su perfección, el motivo de su oración, la santidad que le compete. ${ }^{16}$

«Puesto que todo sacerdote representa a su modo la persona del mismo Cristo, tiene también, al mismo tiempo que sirve a la plebe encomendada y a todo el pueblo de Dios, la gracia singular de poder conseguir más aptamente la perfección de Aquel cuya función representa, y la de que sane la debilidad de la carne humana la santidad del que por nosotros fue hecho Pontífice "santo, inocente, inmaculado, apartado de los pecadores" ( $\mathrm{Hb} \mathrm{7,} \mathrm{26).}$

Cristo, a quien el Padre santificó o consagró y envió al mundo (Jn, 10, 36), “se entregó por nosotros para rescatarnos de toda iniquidad, y adquirirse un pueblo propio y aceptable, celador de obras buenas" (Tit 2, 14), y así, por su pasión, entró en su gloria (Lc 24, 26); semejantemente los presbíteros, consagrados por la unción del Espíritu Santo y enviados por Cristo, mortifican en sí mismos las tendencias de la carne y se entregan totalmente al servicio de los hombres, y de esta forma pueden caminar hacia el varón perfecto, en la santidad con que han sido enriquecidos en Cristo» (PO 12). 
La misión, pues, exige la caridad. Pero ¿cuál es la misión en sentido objetivo? Para Jesús, dejado ya el sacrificio del que hemos hablado, como Palabra del Padre, la primera misión es la Palabra, de modo que su Palabra y su Muerte son una misma cosa, y también su Resurrección. En la Muerte nos ha manifestado su amor y en su Resurrección hemos conocido su amor que perdona a los enemigos. Y todo lo que significa algo es palabra. Y nadie negará que la Muerte y la Resurrección son manifestaciones, significaciones de un ser y de un pensar. Dios ha hablado con la Cruz y la Resurrección de su Hijo. Mas todo ello, como es Palabra, y la Palabra de Dios no miente, se realizó al morir y resucitar.

Pero también antes, en la Última Cena. No era diversa la entrega de ese instante con la del día siguiente. Pero el Sacramento es precisamente un signo que da lo que significa porque viene de Dios. Por eso, esa Palabra realizada es, a la vez que Palabra, y fundamentalmente, sacramento, porque este realiza lo que significa. Los sacramentos de la Iglesia, por eso, no pueden ser otra cosa que realizaciones en el tiempo de lo que este Sacramento, la Eucaristía, es para siempre, el don de Dios al hombre.

Así, la misión de Jesús es convencer y sanar, es decir, llamar al hombre a su profunda vocación y cumplirla. La profunda vocación del hombre es volver a Dios de quien se había separado por la soberbia y la desobediencia, a través de un amor que surge en él y de una fe que le invita a la confianza y a la esperanza. Ello le sana, y le da alegría y fortaleza contra la tentación. Dicho con palabras clásicas: Cristo Profeta se realiza por Cristo Sacerdote, y ambos por Cristo Rey, es decir, Pastor que ahora es obedecido.

Tal misión se realiza en realidad, de otro modo, pero complementario, por todo cristiano que sigue a Cristo. Adquiere, por el bautismo, y responde, a la vocación inicial a la que la Gracia le llamaba, 
convirtiéndose en hijo de Dios y Cuerpo de Cristo. Viene a habitar en él el Espíritu que clama dentro de él «Abba, Padre» y le da sentimientos de hijo de Dios. Se convierte así en signo de Cristo ante el mundo, Palabra Realizada, profeta y sacerdote, puesto que no solo habla del amor de Dios, sino que habla con Dios e intercede. En este sentido, no solamente es pastor de sí mismo, ya que reduce sus pasiones a la obediencia, sino pastor, en algún sentido, de otros hermanos, como una oveja atrae a las demás ovejas en la obediencia al único Pastor, y en la única Iglesia. ${ }^{17}$ Esa obediencia es el sacrificio al que Dios no ha llamado y que unido al de Cristo, da gloria al Padre. El sacerdote está justamente para conseguir y ofrecer a Dios esa oblación de todos los hombres, especialmente a través de la Eucaristía. ${ }^{18}$

De ahí que esa misión que se realiza de modo especial en el presbítero, puesto que, como pastor, y no como mercenario, vive para las ovejas y cumple la misión de Cristo, Cabeza y Pastor, significa que, como el Buen Pastor, da la vida por las ovejas; es decir, le cumple la misión de víctima. Él está llamado al amor de Dios, no únicamente al amor a Dios que le hace hermano, sino al amor del mismo Cristo que le hace Padre y Pastor (Jn 10, 1-21), capaz de amar hasta dar la vida. Ese amor y el discernimiento necesario, son la Gracia de la que habla la Presbyterorum ordinis como propia del presbítero.

17 «Por participar en su grado del ministerio de los apóstoles, Dios concede a los presbíteros la gracia de ser entre las gentes ministros de Jesucristo, desempeñando el sagrado ministerio del Evangelio, para que sea grata la población de los pueblos, santificada por el Espíritu Santo (Rom, 15, 16). Pues por el mensaje apostólico del Evangelio se convoca y congrega el Pueblo de Dios, de forma que, santificados por el Espíritu Santo todos los que pertenecen a este Pueblo, se ofrecen a sí mismos "como hostia viva, santa; agradable a Dios" (Rom., 12, 1)» (PO 2).

18 «Por el ministerio de los presbíteros se consuma el sacrificio espiritual de los fieles en unión del sacrificio de Cristo, Mediador único, que se ofrece por sus manos, en nombre de toda la Iglesia, incruenta y sacramentalmente en la Eucaristía, hasta que venga el mismo Señor (1 Cor, 11, 26)» (PO 2). 


\section{LA EUCARISTÍA, SENTIDO DE LA VIDA DEL PRESBÍTERO EN SU ACCIÓN PASTORAL}

El presbítero es así un hombre eucarístico. La eucaristía es el sentido de la vida del Dios Encarnado. Vino al mundo para dar la vida y para en ese don encontrarse con los hombres. El encuentro se produjo en la Cruz, pero, misteriosamente la Cruz fue precedida por la Eucaristía y seguida por la Resurrección, la Ascensión y Pentecostés. La primera, la Eucaristía, daba sentido a la segunda, a la Cruz, y la segunda, la Cruz, a la tercera, la Resurrección. Esta última tenía un sentido, la fe de los Apóstoles, pero una vez lograda, la desaparición visible del Señor significó y fue seguida del don del Espíritu y el comienzo de la Iglesia.

Digámoslo con palabras del Concilio:

A este sacrificio se ordena y en él culmina el ministerio de los presbíteros. Porque su servicio, que surge del mensaje evangélico, toma su naturaleza y eficacia del sacrificio de Cristo y pretende que «todo el pueblo redimido, es decir, la congregación y sociedad de los santos ofrezca a Dios un sacrificio universal por medio del Gran Sacerdote, que se ofreció a sí mismo por nosotros en la pasión, para que fuéramos el cuerpo de tan sublime cabeza» (PO2).

La Eucaristía es la entrega de Jesús, perpetua, anterior y posterior a la Cruz que fue su entrega cruenta y efectiva, y continúa en el logro de la fe y en el don del Espíritu. Esa es la tarea del presbítero: entregarse, sufrir por la oveja, para lograr su fe y poder darle el Espíritu y así formar, como miembro de Cristo, la Iglesia. Por eso, la Eucaristía es la gran tarea del 
presbítero, porque le une a Cristo orante, y, misteriosamente, santifica con Cristo a su rebaño.

Es una tarea ante Dios y ante los hombres. Ante Dios es por la intercesión eucarística; ante los hombres, porque en favor de ellos se ha dado el Acontecimiento de la entrega del Señor, en favor de cada hombre, de cada oveja perdida, por la que se dejan las noventa y nueve como si fuese única, pero que se trae al rebaño para que forme un solo rebaño y aprenda a amar a las demás ovejas.

Es evidente que, ante esta perspectiva, resulta ridícula la envidia que tiene el laico por el sacerdote y que apareció en tiempo de Lutero. ${ }^{19}$ Mas el Concilio, declarando que el sacerdocio del Nuevo Testamento, tanto el común como el ministerial, se caracterizan por el servicio, la oblación y el amor, destruye el motivo principal de la objeción luterana.

Así pues, con decisión, el Concilio intenta evitar, por un lado, la falsa concepción luterana de que el sacramento del orden es una invención interesada y, por otro lado, indica que el sentido del sacerdocio cristiano, especialmente el ministerial, es el servicio al sacerdocio común. Es decir, ser una Palabra de Cristo para los fieles, y acoger en una sola ofrenda, la de Cristo, la del cuerpo de Cristo que es su Iglesia, siendo ellos mismos ofrenda y víctima agradable. La idea, pues, es que el sacerdocio es un oficio de amor. $^{20}$

19 «Ataquemos, en primer lugar, la primera muralla. Se han inventado que el papa, los obispos, los sacerdotes y los habitantes de los conventos se denominan el orden eclesiástico y que los príncipes, los señores, los artesanos y los campesinos forman el orden seglar lo cual es una sutil y brillante fantasía» (Lutero en A la nobleza cristiana de la nación alemana).

20 El oficio es bien concreto: orar, predicar, celebrar, servir. Mas la perspectiva es el Reino que se consumará en la Parusía y la intención que los hombres entren en él, pues en eso consiste la gloria y la obediencia al Padre. «En consecuencia, los presbíteros, ya se entreguen a la oración y a la adoración, ya prediquen la palabra, ya ofrezcan el sacrificio 


\section{Diferencia del modo de predicar del presbitero y del laico}

El presbítero se entiende unido al Obispo de quien es cooperador (PO2). Por tanto, no es un ministerio distinto aunque sea distinto su grado. Así, la forma de predicar del presbítero debe ser semejante a la suya. $\mathrm{Y}$ ¿cómo predica el Obispo? Su palabra, en razón de su oficio de pastor, tiene una especial autoridad ${ }^{21}$ y es testigo de la verdad única. En consecuencia, independientemente de su especial capacidad intelectual, cada presbítero ejerce su oficio de pastor cuando predica aquello que ha recibido por la tradición de la Iglesia y, unido a su Obispo, adecua a cada momento histórico y personas concretas la verdad inconmovible de la fe. No deben,

eucarístico, ya administren los demás sacramentos, ya se dediquen a otros ministerios para el bien de los hombres, contribuyen a un tiempo al incremento de la gloria de Dios y a la dirección de los hombres en la vida divina. Todo ello, procediendo de la Pascua de Cristo, se consumará en la venida gloriosa del mismo Señor, cuando El haya entregado el Reino a Dios Padre (1 Cor 15, 24)».

21 LG 23: «El cuidado de anunciar el Evangelio en todo el mundo pertenece al Cuerpo de los Pastores, ya que a todos ellos, en común, dio Cristo el mandato, imponiéndoles un oficio común, según explicó ya el papa Celestino a los Padres del Concilio de Efeso». LG 25: «Entre los principales oficios de los Obispos se destaca la predicación del Evangelio. Porque los Obispos son los pregoneros de la fe que ganan nuevos discípulos para Cristo y son los maestros auténticos, o sea los que están dotados de la autoridad de Cristo, que predican al pueblo que les ha sido encomendado la fe que ha de ser creída y ha de ser aplicada a la vida, y la ilustran bajo la luz del Espíritu Santo, extrayendo del tesoro de la Revelación cosas nuevas y viejas (Cf. Mt 13, 52), la hacen fructificar y con vigilancia apartan de su grey los errores que la amenazan (Cf. 2 Tm 4,1-4). Los Obispos, cuando enseñan en comunión con el Romano Pontífice, deben ser respetados por todos como testigos de la verdad divina y católica; los fieles, por su parte, en materia de fe y costumbres, deben aceptar el juicio de su Obispo, dado en nombre de Cristo, y deben adherirse a él con religioso respeto... Aunque cada uno de los Prelados no goce por si de la prerrogativa de la infalibilidad, sin embargo, cuando, aun estando dispersos por el orbe, pero manteniendo el vínculo de comunión entre sí y con el sucesor de Pedro, enseñando auténticamente en materia de fe y costumbres, convienen en que una doctrina ha de ser tenida como definitiva, en ese caso proponen infaliblemente la doctrina de Cristo». 
por tanto, porque no tienen autoridad propia, enseñar como de Cristo opiniones propias.

El laico, posee, aunque de modo distinto, una participación en el sacerdocio de Cristo, es decir en su misión. La misión de Cristo es sacerdotal por tres motivos: (a) intercede ante el Padre, (b) ofrece el sacrificio por antonomasia, el de sí mismo (Aqui estoy, Señor para hacer tu voluntad, como dice Hebreos 10,4-10, rememorando y poniendo en la boca de Cristo las palabras del Salmo 40) y (c) trae la salvación así a los hombres. El ministerio de pastor (profético y real) está unido a este sacerdotal de tal modo que no podría ser Cristo Pastor —es decir, rey y jefe de las ovejas (Hech 5, 2932) —, si primero no fuera sacerdote. Su autoridad de salvar procede de que ha comprado a las ovejas con su sangre y por tanto, le pertenecen (Apo 5,9), y esa presencia multiforme de Cristo salvador se hace presente de modo eminente y único a través de la liturgia. ${ }^{22}$

22 «El punto relativo a la presencia de Cristo en la liturgia aparece en el N. 7 de la Constitución conciliar sobre liturgia: "Para realizar una obra tan grande, Cristo está siempre presente en el sacrificio de la misa, sea en la persona del ministro, 'ofreciéndose ahora por ministerio de los sacerdotes el mismo que entonces se ofreció en la cruz', sea sobre todo bajo las especies eucarísticas. Está presente con su fuerza en los sacramentos, de modo que, cuando alguien bautiza, es Cristo quien bautiza. Está presente en su palabra, pues cuando se lee en la Iglesia la sagrada escritura, es él quien habla. Está presente, por último, cuando la Iglesia suplica y canta salmos, el mismo que prometió: 'Donde están dos o tres congregados en mi nombre, allí estoy yo en medio de ellos' (Mt $18,20)$.

Este texto, inspirado ciertamente en otro de la encíclica Mediator Dei de Pío XII, es retomado posteriormente por Pablo VI y decididamente ampliado en su encíclica Mysterium fidei. En efecto, el Papa, después de hacer referencia al texto conciliar, amplía claramente las formas de presencia de Cristo, no solo en la liturgia, sino en la Iglesia misma. A este propósito Pablo VI afirma que Cristo está presente en la Iglesia que ora, en la Iglesia que se entrega al servicio de los más necesitados, en la Iglesia que camina peregrina a la casa del Padre, en la que predica, en la que dirige y gobierna al pueblo de Dios; pero, de un modo singular, Cristo está presente en la Iglesia que se ofrece y se inmola en el sacrificio de la misa y en la que celebra los sacramentos. De modo eminente Cristo está presente en las especies sacramentales del pan y del vino en la eucaristía. 


\section{CÉSAR BUENDÍA ROMERO}

Inmediatamente, el consejo es complicado. Se trata de no alejarse, pero de no contaminarse; amar al pecador, pero no al pecado; vivir como los demás en todo menos en eso, por ser testigos de una vida nueva que este mundo no puede gozar sin que se le anuncie:

Los presbíteros del Nuevo Testamento, por su vocación y por su ordenación, son segregados en cierta manera en el seno del pueblo de Dios, no de forma que se separen de él, ni de hombre alguno, sino a fin de que se consagren totalmente a la obra para la que el Señor los llama (1 Cor 9, 19-23). No podrían ser ministros de Cristo si no fueran testigos y dispensadores de otra vida distinta de la terrena, pero tampoco podrían servir a los hombres, si permanecieran extraños a su vida y a su condición. (PO)

La segregación propia del que no peca es precisamente la forma de atraer a las ovejas perdidas (¿qué las podría atraer del pecado en los presbíteros?). Asimismo, la forma más idónea con el fin de guardar esa libertad necesaria para que las ovejas tengan un ejemplo de una vida feliz y entregada son los consejos. Especialmente, lo son aquí el de la pobreza y

Esta variedad de formas de presencia no es indiscriminada o indiferente. Son formas de presencia diversas y jerarquizadas. No todas tienen el mismo valor, evidentemente. Pero, eso sí, todas son formas de presencia real. Lo afirma el papa de manera taxativa. Finalmente es importante tomar buena nota de que todos estos modos de presencia se hacen realidad en la Iglesia. Quiero decir con ello que es en la Iglesia y a través de ella donde el Señor se hace sentir, donde el Señor actúa, donde sale al encuentro del creyente y establece con él vínculos profundos de comunión. Es, sobre todo, en la Iglesia que celebra los misterios del culto donde se hace presente y actúa toda la fuerza salvadora y renovadora de la pascua» (Bernal 2013: párrs. 3-5). 
el amor, que incluye, naturalmente, el conocimiento, el interés, el tiempo dedicado, la afabilidad...:

Su mismo ministerio les exige de una forma especial que no se conformen a este mundo (Rom 12, 2); pero, al mismo tiempo, requiere que vivan en este mundo entre los hombres, y, como buenos pastores, conozcan a sus ovejas, y busquen incluso atraer a las que no pertenecen todavía a este redil, para que también ellas oigan la voz de Cristo y se forme un solo rebaño y un solo Pastor (Jn 10, 14-16). Mucho ayudan para conseguir esto las virtudes que con razón se aprecian en el trato social, como son la bondad de corazón, la sinceridad, la fortaleza de alma y la constancia, la asidua preocupación de la justicia, la urbanidad y otras cualidades que recomienda el apóstol Pablo cuando escribe: «Pensad en cuanto hay de verdadero, de puro, de justo, de santo, de amable, de laudable, de virtuoso, de digno de alabanza» (Fil $4,8)$. 


\section{REFERENCIAS}

Documentos del Concilio Vaticano II

\section{Constituciones}

1964 Lumen gentium. Disponible en <http://www.vatican.va/ archive/hist_councils/ii_vatican_council/documents/vat-ii_ const_19641121_lumen-gentium_sp.html>.

1965 Dei Verbum. Disponible en <http://www.vatican.va/ archive/hist_councils/ii_vatican_council/documents/vat-ii_ const_19651118_dei-verbum_sp.html>.

1965 Gaudium et Spes. Disponible en <http://www.vatican.va/ archive/hist_councils/ii_vatican_council/documents/vat-ii_ const_19651207_gaudium-et-spes_sp.html>.

\section{Decretos}

I 965

Presbyterorum ordinis. Sobre el ministerio y la vida de los presbiteros. Disponible en <http://www.vatican.va/archive/hist_councils/ ii_vatican_council/documents/vat-ii_decree_19651207_ presbyterorum-ordinis_sp.html>. 
Pascendi. Carta encíclica del Sumo Pontífice Pío X sobre las doctrinas de los modernistas. Disponible en <http://www. vatican.va/holy_father/pius_x/encyclicals/documents/hf_p-x_ enc_19070908_pascendi-dominici-gregis_sp.html>.

1963 Sacrosanctum Concilium. Sobre la sagrada liturgia. <http://www. vatican.va/archive/hist_councils/ii_vatican_council/documents/ vat-ii_const_19631204_sacrosanctum-concilium_sp.html>.

2000 Dominus Iesus. Sobre la unicidad y la universalidad salvifica de Jesucristo y de la Iglesia. Disponible en <http://www.vatican.va/ roman_curia/congregations/cfaith/documents/rc_con_cfaith_ doc_20000806_dominus-iesus_sp.html>.

\section{BibliogRAFía COMPLEMENTARIA}

AA. VV.

1966

Comentarios a la Constitución sobre la Iglesia Madrid: BAC.

AA. VV.

1969

La libertad religiosa. Taurus. Salamanca.

Aguilar Navarro, Mariano et al.

1967 Comentarios de cuadernos para el diálogo al Esquema XIII. Madrid: Edicusa. 
Alcalá, Manuel

1998 Sinodos, concilios, iglesias. Madrid: BAC 2000.

ANTÓn, Ángel

1987 El Misterio de la Iglesia. Evolución histórica de las ideas eclesiológicas Madrid: BAC.

Congar, Yves y M. Peuchmaurd (eds.)

1970 La Iglesia en el mundo de hoy. 3 tomos. Salamanca: Taurus.

Dupuy, Bernard et ál.

1970 La revelación divina. Taurus. Salamanca.

\section{Frisque, J. e Yves Congar}

1969 Los sacerdotes. Salamanca: Taurus.

GonzÁlez Montes, Adolfo

2008 Imagen de Iglesia. Eclesiología en perspectiva ecuménica. Madrid: BAC.

Herrera Oria, Ángel (dir.)

1968 Concilio Vaticano II. Comentarios a la constitución "Gaudium et Spes» sobre la Iglesia en el mundo actual. Madrid. 
EL SACERDOCIO DE LOS FIELES Y EL MINISTERIAL EN EL PRIMER CAPÍTULO DE LA PRESBYTERORUM ORDINIS

Jossua, Jean-Pierre e Yves Congar (eds.)

1969 La liturgia después del Vaticano II. Salamanca: Taurus.

LATOURELLE, René

1989 Vaticano II, Balance y Perspectivas. Veinticinco años después (19621987) Salamanca: Colección Verdad e Imagen. Sígueme.

Martín Descalzo, José Luis

1967 El concilio de Juan y Pablo. Documentos pontificios sobre la preparación, desarrollo e interpretación del Vaticano II. Madrid: BAC.

Rovira Belloso, Josep M.

1997 Vaticano II, un concilio para el tercer milenio. Madrid: BAC 2000.

SCHÖKEL, Alonso (ed.)

1969

Comentarios a la "Dei Verbum» sobre la divina revelación. Madrid: BAC. 